\title{
The effects of roadside structures on the transport and dispersion of ultrafine particles from highways
}

\author{
George E. Bowker ${ }^{\mathrm{a}}$, Richard Baldauf ${ }^{\mathrm{b}, \mathrm{c}, *}$, Vlad Isakov ${ }^{\mathrm{d}}$, \\ Andrey Khlystov ${ }^{\mathrm{e}}$, William Petersen ${ }^{\mathrm{f}}$ \\ ${ }^{a}$ US Environmental Protection Agency, Office of Research and Development, National Exposure Research Laboratory, \\ Atmospheric Modeling Division, USA \\ ${ }^{\mathrm{b}}$ US Environmental Protection Agency, Office of Research and Development, National Risk Management Research Laboratory, USA \\ ${ }^{\mathrm{c}}$ US Environmental Protection Agency, Office of Air and Radiation, Office of Transportation and Air Quality, USA \\ ${ }^{\mathrm{d}}$ NOAA/Atmospheric Sciences Modeling Division (In Partnership with the US Environmental Protection Agency), USA \\ ${ }^{\mathrm{e}}$ Department of Civil and Environmental Engineering, Pratt School of Engineering, Duke University, USA \\ ${ }^{\mathrm{f}}$ William Petersen, Consultants, Hurdle Mills, NC, USA
}

Received 14 March 2007; received in revised form 20 June 2007; accepted 27 June 2007

\begin{abstract}
Understanding local-scale transport and dispersion of pollutants emitted from traffic sources is important for urban planning and air quality assessments. Predicting pollutant concentration patterns in complex environments depends on accurate representations of local features (e.g., noise barriers, trees, buildings) affecting near-field air flows. This study examined the effects of roadside barriers on the flow patterns and dispersion of pollutants from a high-traffic highway in Raleigh, North Carolina, USA. The effects of the structures were analyzed using the Quick Urban \& Industrial Complex (QUIC) model, an empirically based diagnostic tool which simulates fine-scale wind field and dispersion patterns around obstacles. Model simulations were compared with the spatial distributions of ultrafine particles (UFP) from vehicular emissions measured using a passenger van equipped with a Differential Mobility Analyzer/Condensation Particle Counter. The field site allowed for an evaluation of pollutant concentrations in open terrain, with a noise barrier present near the road, and with a noise barrier and vegetation present near the road.

Results indicated that air pollutant concentrations near the road were generally higher in open terrain situations with no barriers present; however, concentrations for this case decreased faster with distance than when roadside barriers were present. The presence of a noise barrier and vegetation resulted in the lowest downwind pollutant concentrations, indicating that the plume under this condition was relatively uniform and vertically well-mixed. Comparison of the QUIC model with the mobile UFP measurements indicated that QUIC reasonably represented pollutant transport and dispersion for each of the study configurations.
\end{abstract}

(C) 2007 Elsevier Ltd. All rights reserved.

Keywords: Air quality; Dispersion modeling; Noise barriers; Vegetation; Mobile sources; QUIC

\footnotetext{
*Corresponding author. US Environmental Protection Agency, Office of Research and Development, National Risk Management Research Laboratory, MD-E343-02, Research Triangle Park, NC 27711, USA. Tel.: + 919541 4386; fax: + 9195410359.

E-mail address: baldauf.richard@epa.gov (R. Baldauf).
} 


\section{Introduction}

In recent years, a number of human epidemiological studies have reported associations between population's proximity to high-traffic roadways and adverse health effects that include respiratory, cardiovascular, birth, cancer, and mortality impacts (e.g., Pearson et al., 2000; Wilhelm and Ritz, 2003; Peters et al., 2004; Jerrett et al., 2005; McConnell et al., 2006). Several air quality monitoring studies have measured elevated concentrations of a number of air pollutants near roadways including ultrafine particles (UFP, aerodynamic diameter $<0.1 \mu \mathrm{m}$ ) (Zhu et al., 2002a, b; Sapkota and Buckley, 2003; Kittelson et al., 2004). The majority of particulate matter (PM) mass emitted by motor vehicle combustion occurs in the $\mathrm{PM}_{2.5}$ size range, with mass median diameters generally between 0.1 and $0.2 \mu \mathrm{m}$ for gasoline and diesel vehicles (Cadle et al., 1999; Durbin et al., 1999; Kleeman et al., 2000). The number of particles emitted by gasoline and diesel vehicles occurs primarily in the UFP size range, so the occurrence of high concentrations of these particles near the road likely represents primary combustion emissions from motor vehicles on that road. As a first approximation, we used the number concentration of UFP to examine initial dispersion patterns from the roadway.

The initial dispersion of pollutants from traffic emissions will likely be affected by vehicularinduced turbulence (Kalthoff et al., 2005) and by local obstacles, such as noise barriers, buildings, and vegetation. These barriers are common features of high-traffic roadways, particularly those which run through populated areas. These features may block dispersion, increase turbulence and initial mixing, and filter or otherwise enhance deposition (Tan and Lepp, 1977; Madders and Lawrence, 1985; Veerabhadra Swamy and Lokesh, 1993; Hölscher et al., 1993). Wind perpendicular to the barrier may lead to an upward deflection of air flow caused by the structure, which could increase the apparent release height of the pollutant and increased vertical mixing due to the flow separation at the top of the barrier (Lidman, 1985). In addition, a recirculation cavity forms in the lee of the structure. For noise barriers, studies have reported that this recirculation cavity can extend between 3 and 12 wall heights downwind, be well-mixed and often has substantially lower pollutant concentrations (between $0 \%$ and $80 \%$ of the roadside values) (Nokes and Benson, 1984; Paul-Carpenter and Barboza, 1988; Hölscher et al., 1993; Veerabhadra Swamy and Lokesh, 1993).

A number of regulatory line source dispersion models used in vehicular traffic assessments exist (e.g., CALINE, Benson, 1992; Nagendra and Khare, 2002). These models are simple Gaussian plume models, and do not explicitly simulate the complex flows around individual structures. Thus, these models may not adequately represent local near-roadway concentrations for common complex road configurations within the first few hundred meters from roadside obstacles.

The objective of this study was to explore the effects of roadside obstacles on the near-field dispersion patterns of traffic emissions. We used two independent methods to investigate the effect of a barrier on pollutant concentrations with wind perpendicular from the road: fine-scale numerical modeling and direct measurements of UFP using a mobile monitor.

\section{Modeling approach}

Characterizing the dispersion in the near road environment requires the use of modeling tools capable of resolving complex flow patterns induced by roadside barriers. We used the fast-response, mass-consistent diagnostic wind-field model Quick Urban \& Industrial Complex (QUIC) (version 4.3; Los Alamos National Laboratory/University of Utah) to simulate the airflow patterns and dispersion of pollutants in the near-road environment and explore the effects of roadside barriers on air quality. QUIC predicts the airflow patterns and resulting dispersion of contaminants within complex urban areas (Pardyjak and Brown, 2003; Pardyjak et al., 2004; Williams et al., 2005a, b; Gowardhan et al., 2006). QUIC predicts velocities and concentrations at uniformly spaced grid cells throughout a complex three dimensional domain of interest. The predictions are time-averaged and represent steadystate conditions.

In this study, we used the QUIC model to simulate transport and dispersion of pollutants from a portion of a roadway running through a suburban area. The EPA conducted a field study in July and August, 2006, near a heavily-traveled (125,000 vehicles per day) 8-lane segment of Interstate 440 (I-440) in Raleigh, North Carolina, USA $\left(35^{\circ} 49^{\prime} 28^{\prime \prime} \mathrm{N}, 78^{\circ} 36^{\prime} 54^{\prime \prime} \mathrm{W}\right)$ (Fig. 1). Mobile monitoring and on-site meteorological measurements were made as part of this field study. 


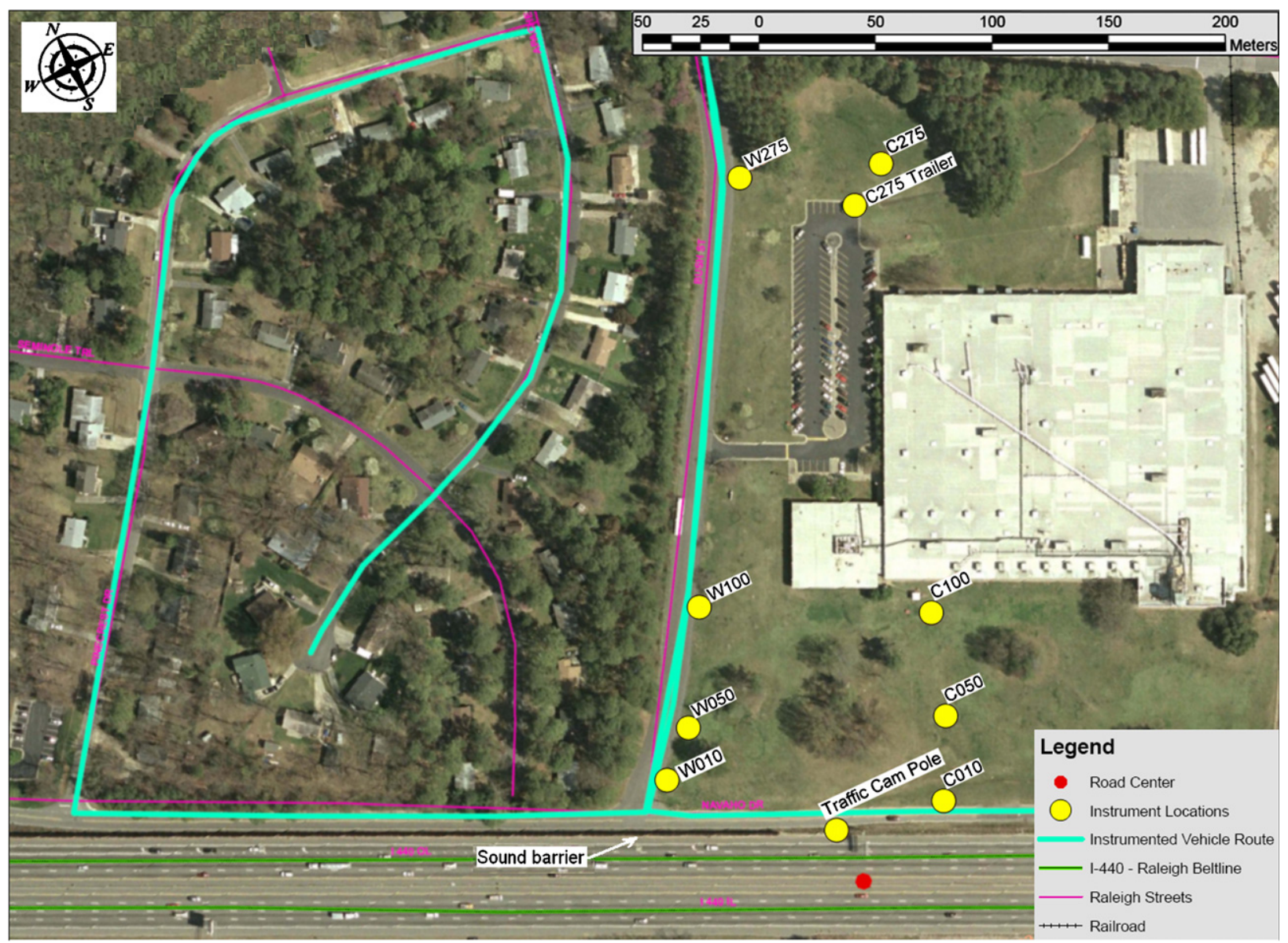

Fig. 1. Aerial map of the near-road field study site along I-440 in Raleigh, North Carolina showing locations of mobile measurements (teal) using a GPS sensor.

The domain contained two adjacent land-use classes downwind from the road: (1) an open mowed-grass lawn with a few isolated stands of trees and no roadside barriers with a wide singlestory building (used as an adult educational facility) occupying the central open area $\sim 120 \mathrm{~m}$ away from the road and (2) a suburban neighborhood with many tall trees interspersed among one- and twostory houses and a noise barrier adjacent to the highway.

For the QUIC simulations, we modeled the domain at $2-\mathrm{m}$ resolution $(700 \mathrm{~m}$ along the road by $500 \mathrm{~m}$ away from the road by $50 \mathrm{~m}$ in height) that included the field study site measurement locations (Fig. 2). Within QUIC, the complex geometry of the site was modeled using solid non-permeable simple shapes (blocks and cylinders). We explored the three representations of the field site, each progressively increasing in complexity: (1) A "base" case consist- ing of a uniform flat domain with no obstacles and no noise barrier. (2) A "noise barrier-only" case, where a noise barrier $(6 \mathrm{~m}$ tall, $352 \mathrm{~m}$ long, and $2 \mathrm{~m}$ wide) extended along the domain parallel to the line sources. (3) A representation of the highly complex "field study site" including the barrier, buildings, and vegetation (Fig. 2). The buildings and stands of trees were modeled as solid, non-porous, rectangular blocks, with heights approximated from photographs taken at the site. The locations and lateral dimensions of the blocks were made directly from the aerial photograph (Fig. 2). Vegetation was modeled using solid blocks because QUIC currently has no ability to model "porous" blocks. Care was taken to leave openings between the vegetation blocks to ensure that flow was "disturbed" (with enhanced vertical and lateral mixing) rather than blocked. Solid blocks representing stands of vegetation have been previously used in QUIC simulations 


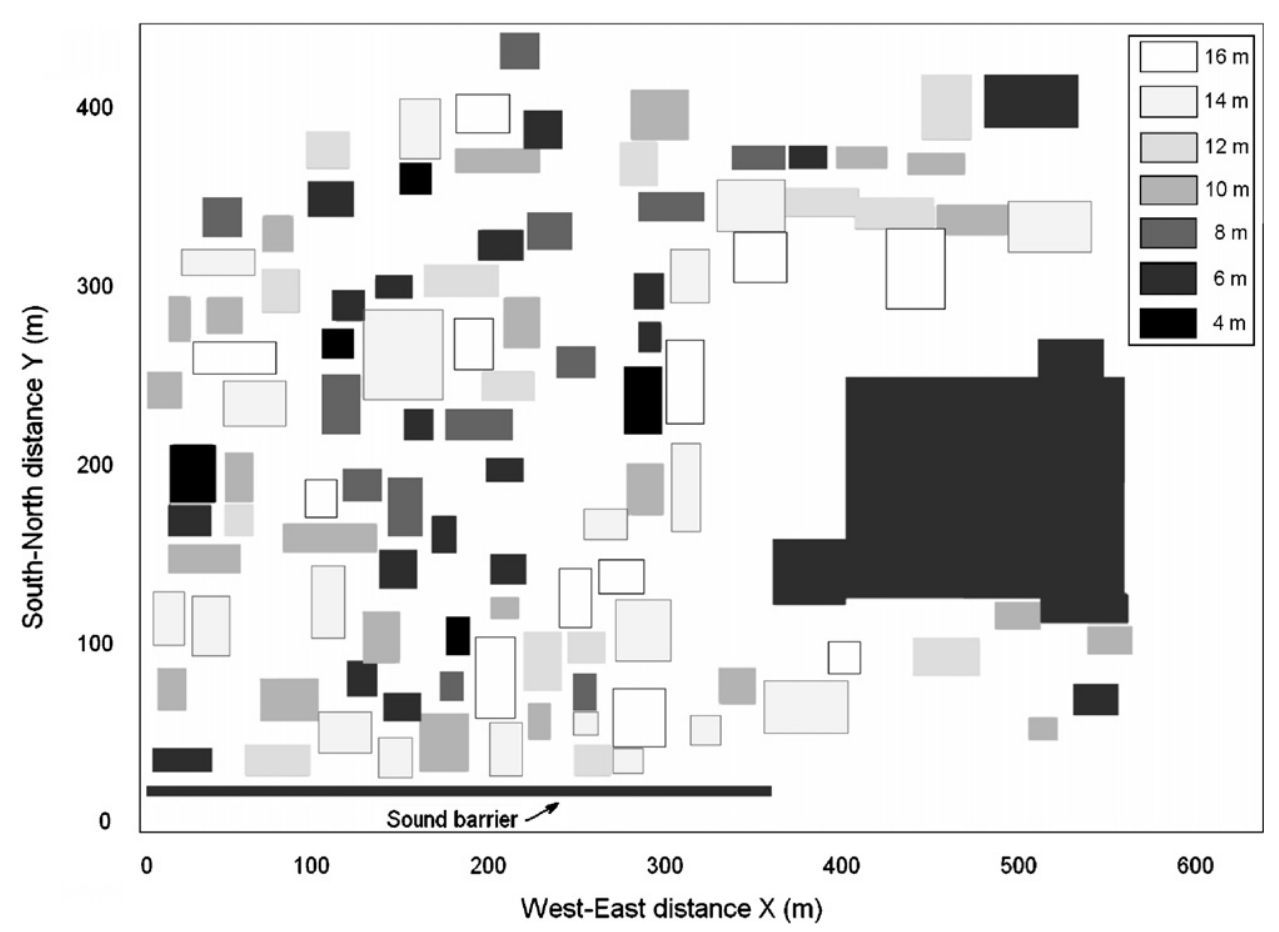

Fig. 2. Plan view of the QUIC modeling domain. The legend indicates the height of the structures.

of wind velocity in the desert (Bowker et al., 2006, 2007).

To predict the flow patterns, QUIC applies an empirical formulation of the flow around each block within the geometry, and then applies mass conservation to the resulting flow field. The parameterized representation of the flow around an individual block consists of two essential features: (1) a region of slow, recirculating flow on the windward side of the block (Pardyjak and Brown, 2003; Bagal et al., 2004); (2) a large wake-effect region on the leeward side of the block characterized by a recirculating cavity zone as well as a zone of depressed velocities (Pardyjak and Brown, 2003; Pardyjak et al., 2004; Singh et al., 2006). The parameterization for the length of the leeward recirculation zone at ground level, $L_{\mathrm{c}}$, used in QUIC is

$\frac{L_{\mathrm{c}}}{H}=\left(\frac{1.8 \mathrm{~W} / H}{(L / H)^{0.3}(1+W / H)}\right)$,

where $H$ is the height of the barrier, $W$ is the crosswind length of the barrier, and $L$ is the thickness (Pardyjak and Brown, 2003). For the noise barrier in the modeling domain $(6 \mathrm{~m}$ tall, $352 \mathrm{~m}$ long, and $2 \mathrm{~m}$ wide), $L_{\mathrm{c}}$ is about $58.4 \mathrm{~m}$ (9.7 barrier heights).
The velocities around each individual block vary directly in magnitude with the input boundary layer velocity profile. We assume neutral atmospheric stability class and that the input velocity profile is logarithmic

$U_{\text {ref }}=\frac{u_{*}}{\kappa} \ln \left(\frac{z-d}{z_{0}}\right)$,

where $\kappa$ is Von Karman's constant (nominally 0.4 ), $z(7 \mathrm{~m})$ is the height for the reference wind speed $U_{\text {ref }}, u_{*}$ is the friction velocity $\left(\mathrm{m} \mathrm{s}^{-1}\right), z_{0}$ is the roughness length $(\mathrm{m})$, and $d(\mathrm{~m})$ is the zero-plane displacement height (assumed to be zero).

Upwind of the study domain consisted of relatively flat and uniform single-story buildings at a slightly lower elevation than the highway. This downslope resulted in the tops of the buildings being essentially even with the elevation of the surface of the roadway. Although Grimmond et al. (1998) report an average $z_{0}$ of $\sim 0.7 \mathrm{~m}$ for residential, commercial, and mixed use areas in suburban settings, we chose a $z_{0}$ of $0.05 \mathrm{~m}$ as more appropriate to match the flow conditions at the site.

The reference wind speed, $U_{\text {ref }}$, was $2.25 \mathrm{~m} \mathrm{~s}^{-1}$ (with standard deviation $0.3 \mathrm{~m} \mathrm{~s}^{-1}$ ). This value was found by averaging 11 consecutive 10-min average 
wind velocities during the time period the mobile van was taking measurements (7 August 2006 from 8 to 10 AM, EST) used in the model-to-monitor comparisons. The 10-min averages were created from $10 \mathrm{~Hz}$ sonic anemometer measurements collected by an instrument mounted on a trailer $\sim 20 \mathrm{~m}$ from the road at a height of $7 \mathrm{~m}$ above ground. We also determined the average wind direction measured by this sonic anemometer $\left(208^{\circ}\right.$ with a standard deviation of $5^{\circ}$ ). This translates to a wind direction of $180^{\circ}$ in the QUIC coordinate system, exactly perpendicular to the road.

The concentration predictions within QUIC (Williams et al., 2005a, b) were based on following the trajectories of simulated neutrally buoyant "massless" particles released at a rate of 5000 particles per time step (1 s) along two line sources. Each line source $(692 \mathrm{~m}$ long and parallel to the $X$-axis at a height of $1 \mathrm{~m}$ ) was intended to simulate the tail-pipe releases from one of the traffic directions of the highway. The line sources were located at $Y=-20$ and 0,32 and $12 \mathrm{~m}$ away from the noise barrier, respectively. Several line sources were used since QUIC does not simulate rectangular block volume sources, and does not include vehicleinduced turbulence.

Particles released from the line sources underwent a "random-walk" through the domain based on the predicted wind velocity field. The particles also "diffused" based on "turbulence" levels, in part, derived from the model-predicted velocity gradients. The concentration value for a grid cell was calculated by summing the number of particles within the cell at each time step. Within each grid cell, we computed the time-averaged concentration for $900 \mathrm{~s}$ (after a $300 \mathrm{~s}$ time period to reach an equilibrium state).

We varied the time step, grid cell size, averaging time, number of particles released, and placement of the line sources relative to the barrier, resolving the simulations to the point where the time-averaged concentrations were stable and no longer sensitive to small changes in these variables.

\section{QUIC model results}

The QUIC simulations showed the influence of the roadside barriers on the airflow and pollutant dispersion patterns. The time-averaged horizontal dispersion patterns at a height of $1 \mathrm{~m}$ above ground for the three simulations (base, barrier-only, and field-site) are shown in Fig. 3. For all three a

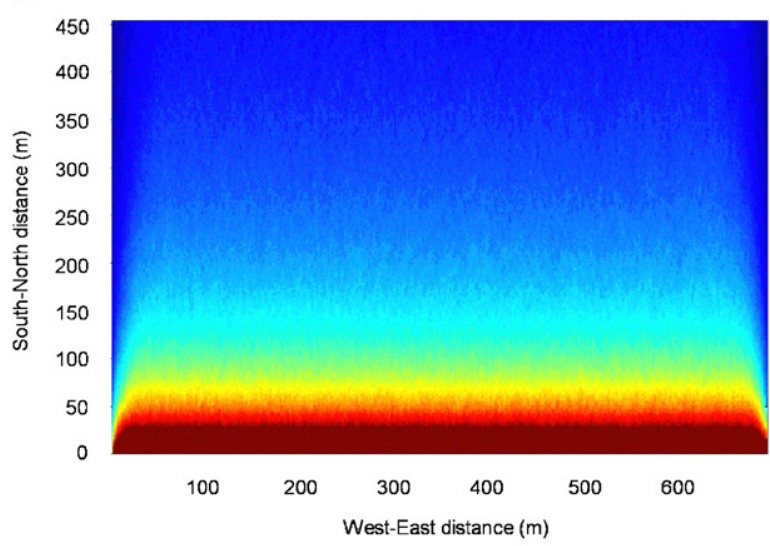

b

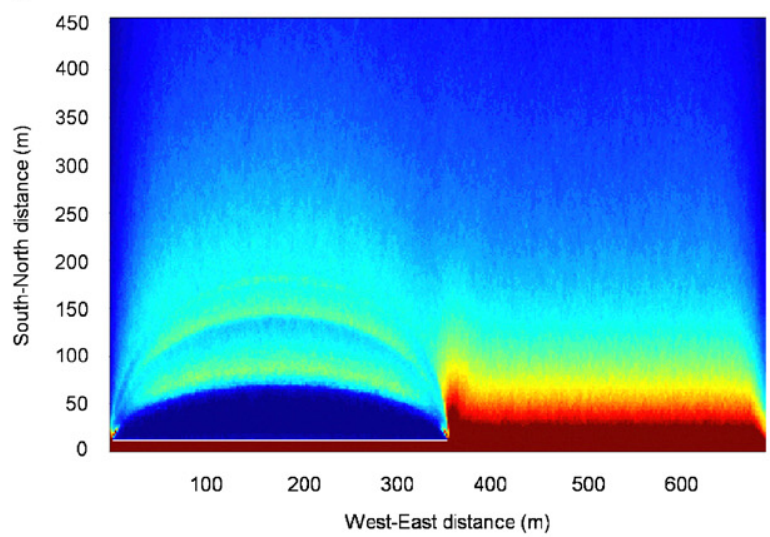

C

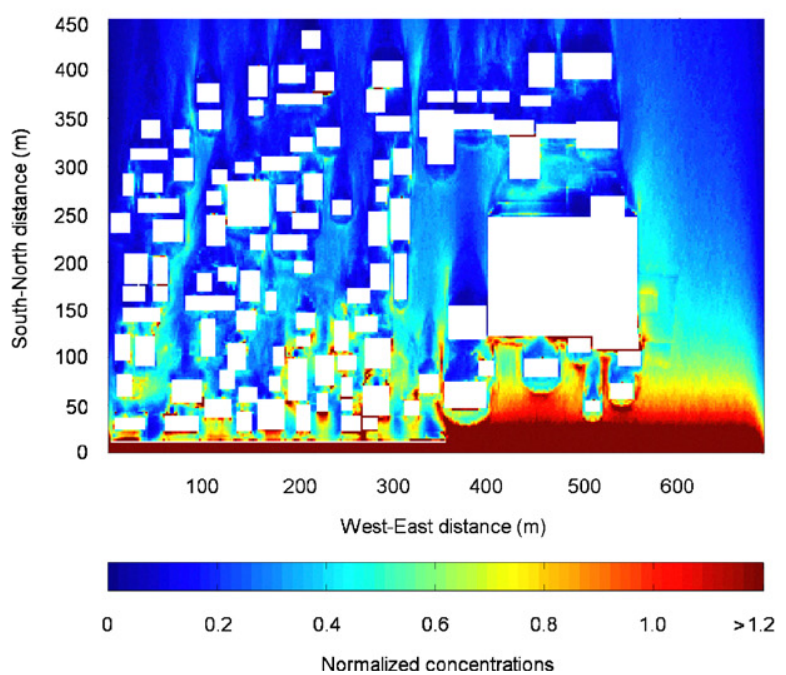

Fig. 3. Plan view showing horizontal concentration patterns simulated in QUIC at a height of $1 \mathrm{~m}$ for the three simulations (a) base case, (b) sound barrier only, and (c) the field site. 
simulations, the QUIC concentration values were normalized by the median concentration value found in the open area of the base simulation at a height $3 \mathrm{~m}$ above ground (which corresponds to the air intake of the mobile van); specifically, the first row of grid cells along the leading edge of the access road, from $X=400$ to $640 \mathrm{~m}$ at $Y=14 \mathrm{~m}$. This location was chosen because the concentrations were quite high, and should favorably compare with the mobile measurements since the emissions from the highway were just moving a short distance across flat, open terrain. Generally, the highest concentrations were seen in close proximity to the highway. High concentrations persisted near the ground in the open areas for all three simulations, but were substantially reduced in the lee of the noise barrier for the barrier-only and field-site simulations.

The patterns of pollution dispersion followed the airflow patterns. The presence of obstacles perturbed the flow streamlines. As expected in the velocity patterns for the noise barrier simulations, the flow streamlines moved vertically up and over the barrier (Fig. 4). A wake region in the lee of the noise barrier was characterized by slow velocities, a recirculation zone, and lower concentrations relative to the base simulation.

Fig. 5 shows vertical cross-sections of modeled concentrations for the three simulations (base, barrier-only, and field-site configurations) in the area behind the barrier. Each vertical cross-section represents the median cross-wind concentration modeled for that portion of the domain. The highest and most-extensive concentrations were seen in the open terrain base simulation, due to the lack of vertical mixing and dispersion of the plume. The wind movement over the noise barrier lifted the plume relative to the base simulation (Fig. 4). The relative concentrations in the lee of the barrier for the three simulations are seen in Fig. 6a, showing horizontal concentration profiles along the lee side of the barrier (median values from $Y=14$ to $34 \mathrm{~m}$ ) at a height of $3 \mathrm{~m}$. The highest concentrations were found for the base simulation, followed by the field-site (barrier with trees) simulation ( $\sim 50 \%$ of the base simulation values), and finally the barrier-only simulation $(\sim 5 \%$ of the base simulation concentrations) (Fig. 6a). Little pollutant mixed down into the recirculation cavity for the barrier-only simulation, leading to extremely low concentrations. Veerabhadra Swamy and Lokesh (1993) found similar patterns for lead deposition around solid and vegetative barriers, showing essentially no lead from traffic emissions in the lee of the barriers.

The concentrations for the barrier-only and fieldsite simulations were approximately the same as the base simulation in the open area near the road (from $X=400$ to $690 \mathrm{~m}$ ) (Fig. 3). Enhanced concentrations were predicted by QUIC where the noise barrier ends (at about $X=350 \mathrm{~m}$ ), suggesting that plume material from the front of the barrier was moving laterally and being swept downwind at the edge of the barrier.

Differences were seen in the concentrations downwind of the barrier recirculation zone area for all three simulations (Figs. 5 and 7a). For the barrier-only simulation, results suggested that after the plume was elevated by the barrier and passed over the recirculation zone, it returned to ground

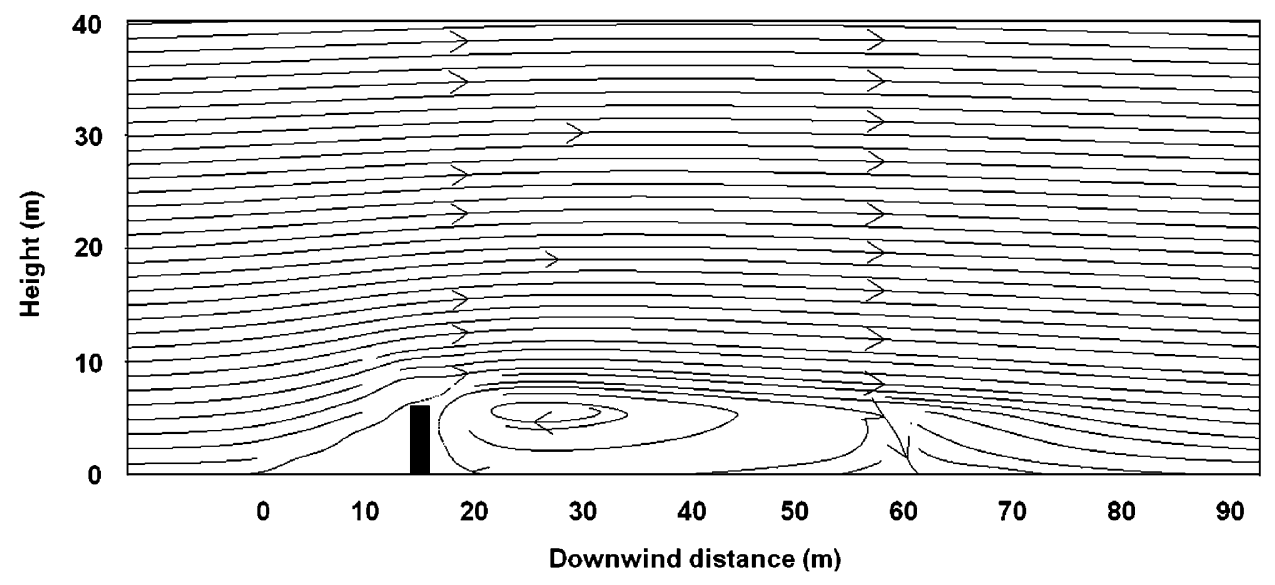

Fig. 4. Elevation view showing flow streamlines for the "barrier only" case. Flow is from left to right. A large recirculation zone is present downwind of the sound barrier. 

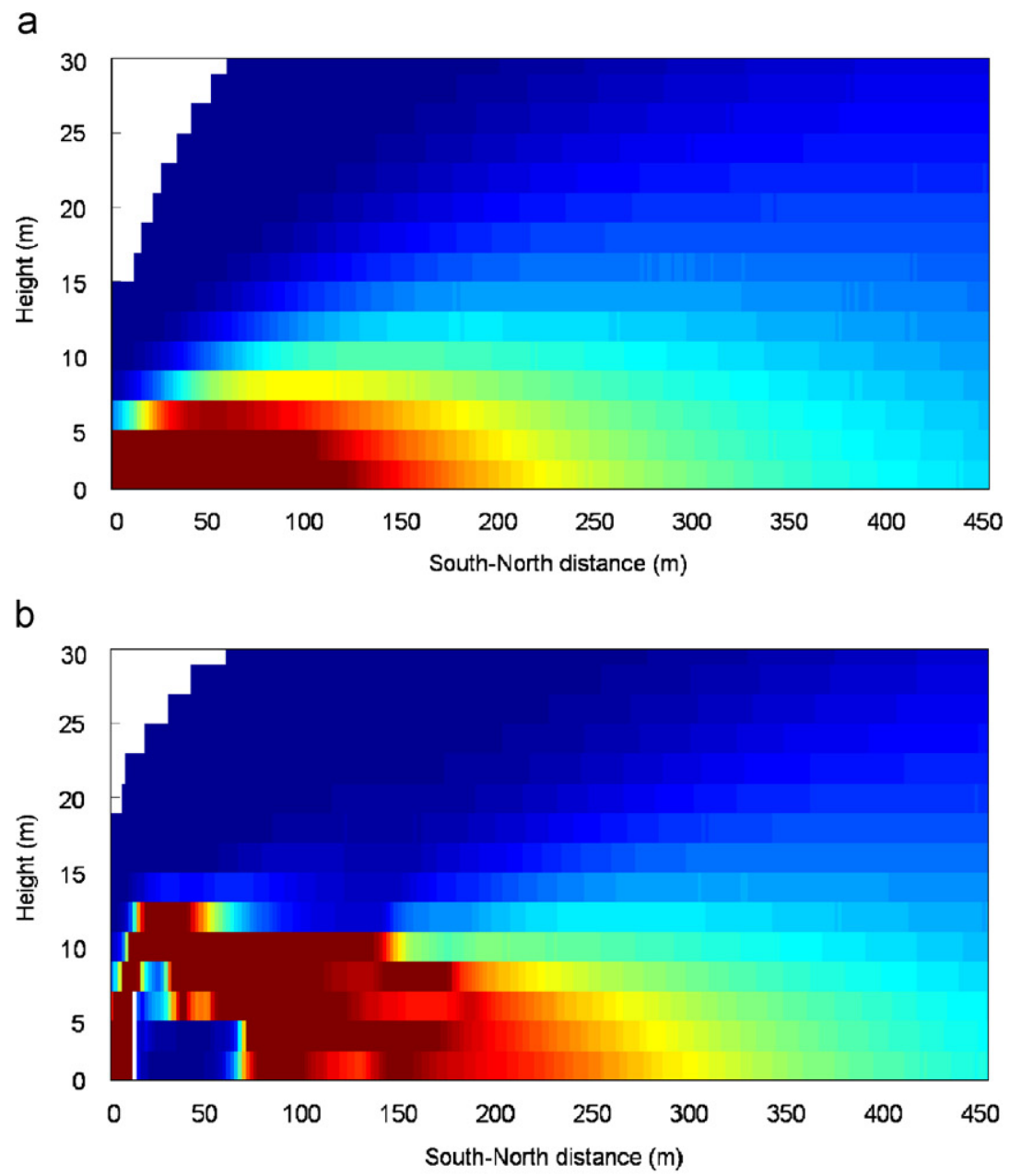

C
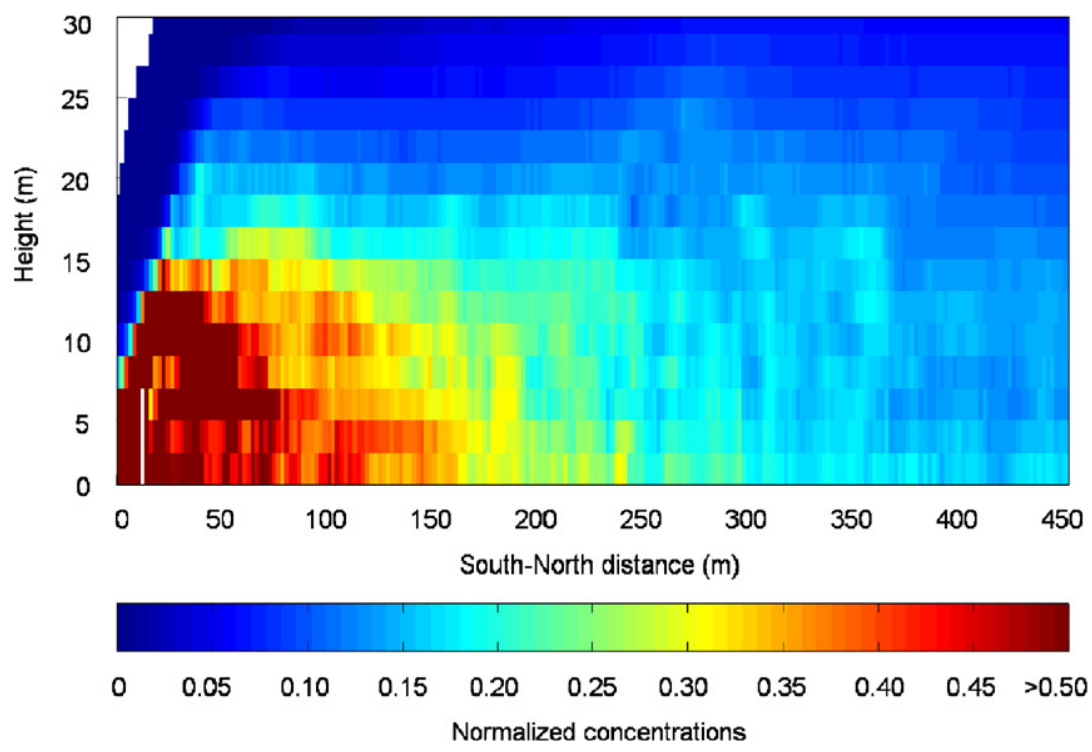

Fig. 5. Vertical alongwind sections showing the median cross-wind concentration behind the barrier as a function of downwind distance for (a) the base, (b) barrier-only, and (c) field site simulations. The line sources are at $X=-20$ and $0 \mathrm{~m}$. The barrier is at $X=12 \mathrm{~m}$. 
a

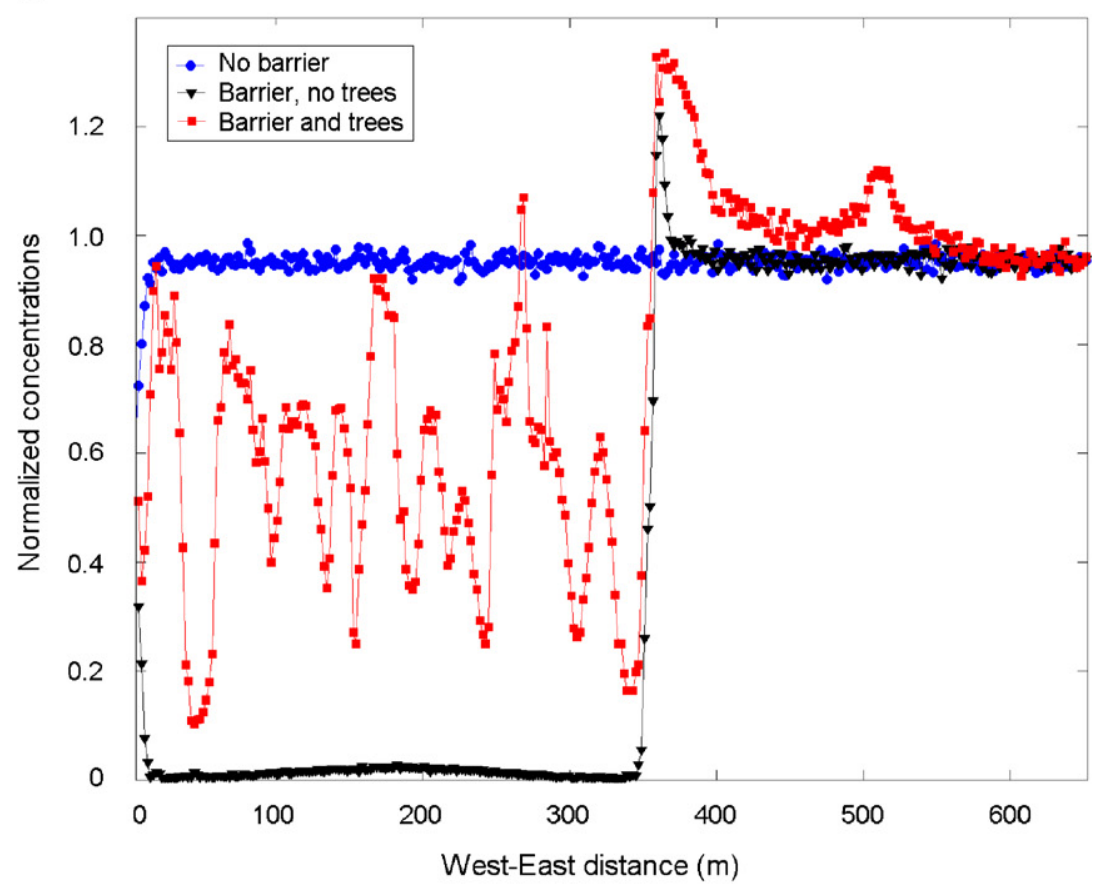

b

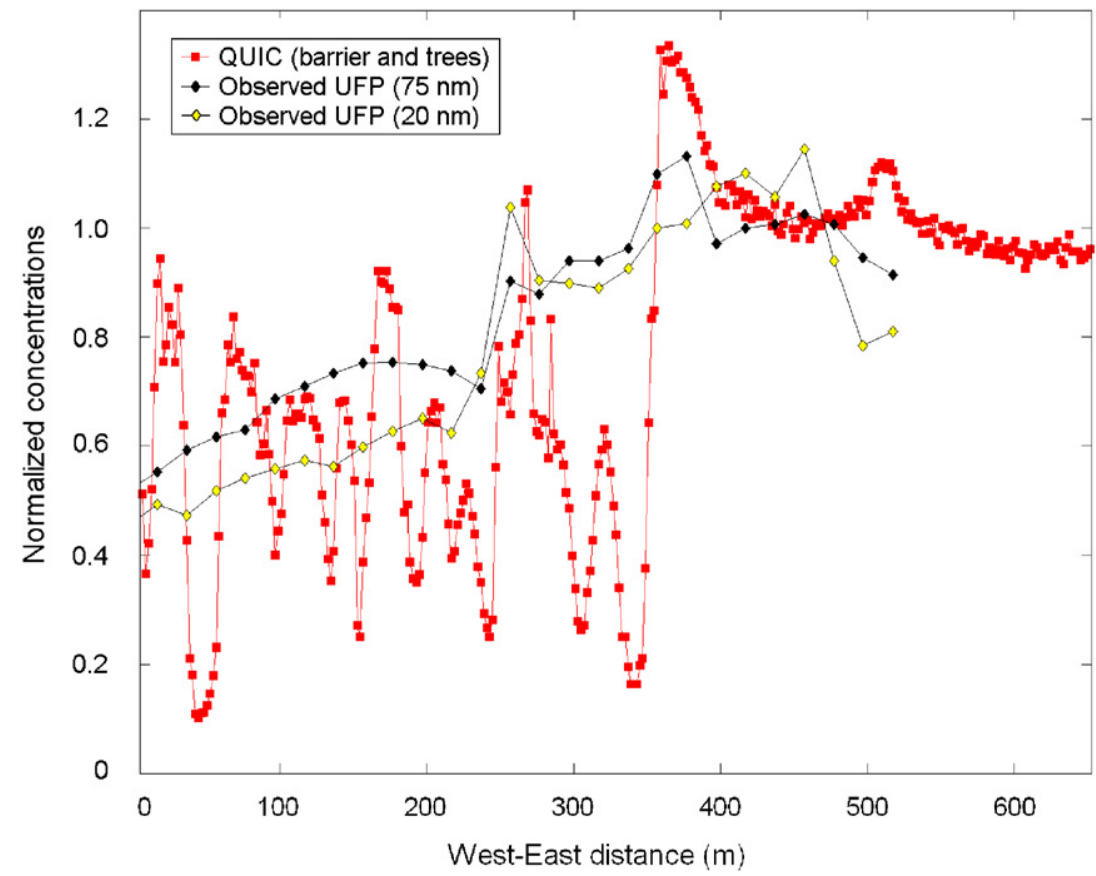

Fig. 6. Normalized cross-wind concentration profiles (at 3-m) taken along the access road parallel to I-440 (median values from $Y=14$ to $34 \mathrm{~m}$ ) for (a) the three different QUIC simulations (base, sound barrier only, and field site), and (b) the mobile measurements for two classes of particulates $(75 \mathrm{~nm}$, black and $20 \mathrm{~nm}$, yellow diamonds) over a 2-h period compared with the QUIC simulation of the field site.

level. Thus, concentrations were $\sim 35 \%$ higher where the plume reattachment occurred $(\sim 80 \mathrm{~m}$ from the second line source at $Y=0$ ) compared with the base simulation. At greater distances from the road, the barrier-only concentrations remained higher, approaching the base simulation values 
a

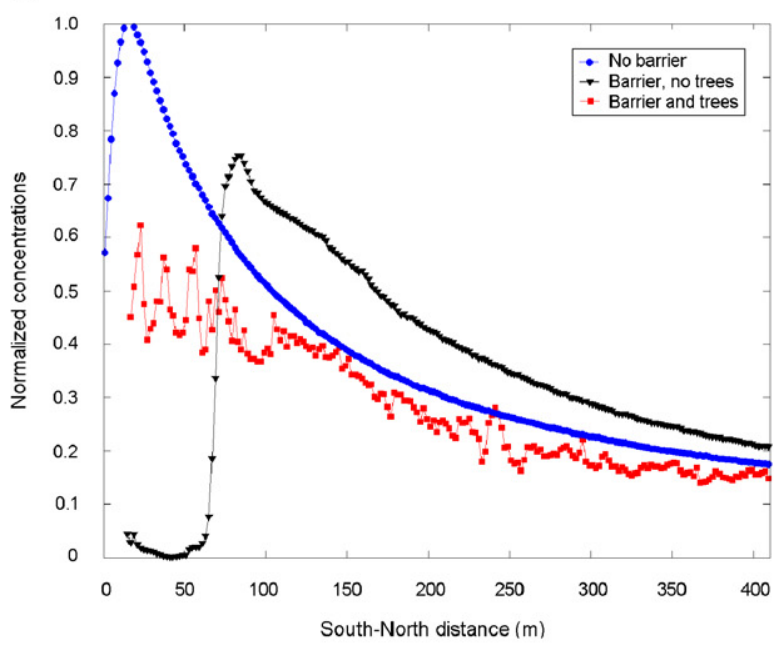

b

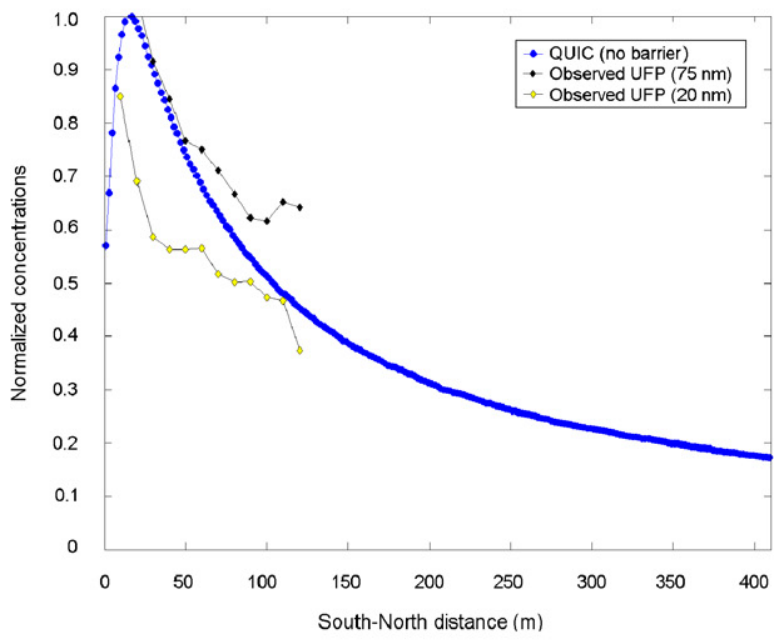

C

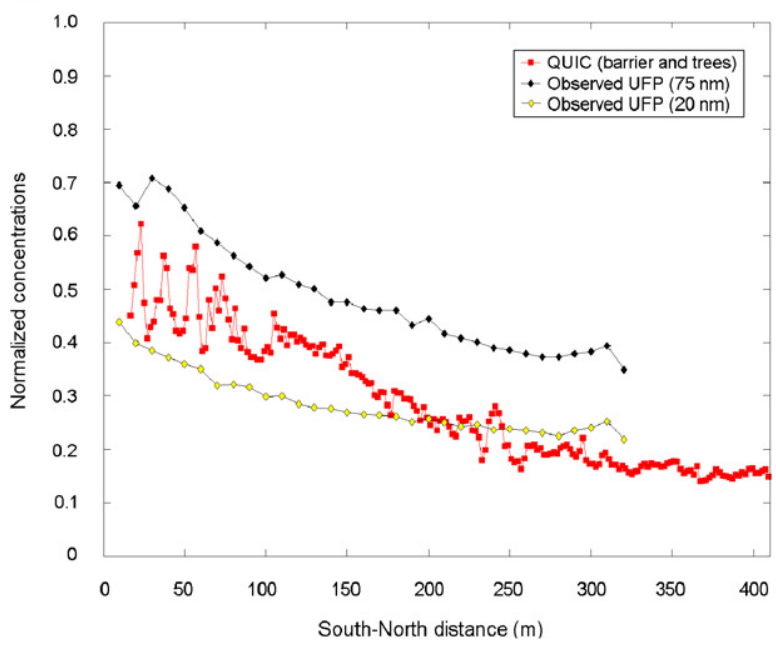

near the edge of the domain (Fig. 7a). The base simulation contrasted with the field-site simulation (noise barrier and vegetation), where the plume was extremely well-mixed vertically after encountering the barrier and going through the trees leading to decreased average concentrations at all downwind distances.

\section{Comparison of model estimates with observations}

Observations from mobile measurements collected at the site were compared with QUIC model predictions to evaluate roadside structure effects and evaluate model results. Fig. 1 shows the route along which a mobile monitoring van identified temporal and spatial patterns of pollution for the complex study domain. Highly time-resolved measurements of UFP were collected while sampling continuously and driving through the domain. The resulting concentrations were recorded as functions of location and time using a global positioning system (GPS). The driving route was selected to cover the two scenarios of interest in the study domain (Fig. 1). By driving through the areas with and without a noise barrier next to the road, and also on transects away from the road that had no barriers and noise barrier and vegetation, the effects of these features on the concentration field were characterized. Because the concentration field varied not only spatially but temporally, the same route was traversed multiple times during the study period, with each route taking generally $10 \mathrm{~min}$ to complete. At a $1 \mathrm{~Hz}$ sampling frequency, this resulted in $\sim 600$ concentration measurements for each route. Since traffic activity on I-440 did not significantly vary over the 10 -min sampling period for each route, we assumed that emission rates during the measurement time periods were relatively constant. For the comparisons with QUIC, we selected a 2-h time period (7 August 2006 from 8 to 10 AM EST) during which the wind was essentially constant and perpendicular from the roadway. To obtain a reliable statistical description of the mean and variability in concentration at each point and to

Fig. 7. Normalized concentrations as a function of downwind distance (at $3 \mathrm{~m}$ ) for: (a) the three different QUIC simulations (base, sound barrier only, and field site); (b) the mobile measurements in the open area and the QUIC model for the base case; and, (c) comparison between mobile measurements and the QUIC model for the field site in the region downwind of the sound barrier in the residential neighborhood. For all cases, the sound barrier is located at $X=12 \mathrm{~m}$. 
create spatial maps of pollutant concentrations, we averaged all the measurements that occurred within each $20 \times 20 \mathrm{~m}^{2}$ area over the course of the measurement time period. Thus, each point comprised the average of $\sim 60$ individual point measurements. A detailed description of the modeling platform and the methodology to create spatial maps is given in Khlystov and Ma (2006).

Number concentrations of 20 and $75 \mathrm{~nm}$ particles were measured using two identical differential mobility analyzer - Condensation Particle Counter (DMA-CPC) combinations. Standard parts from TSI Inc (TSI 3071 DMA and TSI 3010 CPC) were used to build the instruments. The DMAs were operated at $10 \mathrm{~L} \mathrm{~min}^{-1}$ sheath flow rate and $1 \mathrm{~L} \mathrm{~min}^{-1}$ sample flow rate. One DMA was set to a constant voltage, selecting a nearly monodisperse aerosol $20 \mathrm{~nm}$ in diameter. The other DMA was set to a voltage corresponding to $75 \mathrm{~nm}$. The particles selected by the DMAs were counted by the CPCs at $10 \mathrm{~Hz}$. The particle counts were converted to number concentrations using the charging efficiency for the particles at that size. To obtain information on other particle sizes and to assess how the variability at one size compares with the variability at other sizes a limited set of runs were made over the same route during which one instrument was sampling $20 \mathrm{~nm}$ particles at $10 \mathrm{~Hz}$, while the other was operated in the SMPS mode (Wang and Flagan, 1990) measuring the size distribution in the range $12-300 \mathrm{~nm}$ with the time resolution of $20 \mathrm{~s}$.

For the comparison of QUIC model results with observations, we selected two bins from the entire distribution of the observed UFP size range: 20 and $75 \mathrm{~nm}$ particles. All the concentrations from the mobile measurements were normalized by taking the median value in the open area along the access road directly adjacent to the highway. Comparison of normalized measurement data with normalized modeling data allowed for an assessment of pollutant transport and dispersion from the roadway without needing to account for background pollutant concentrations or changes in traffic emission factors over long time-periods.

Similar gradients were identified in the mobile measurements as in the QUIC results (Figs. 6b, 7b and $\mathrm{c}$ ), though minor differences were seen in the absolute magnitudes and rates of decay with distance. In general, the measured concentrations were highest in the open area directly adjacent to I440 , while the concentrations in the lee of the noise barrier at an equivalent distance from the roadway were $\sim 60 \%$ of the concentrations in the open area (Fig. 6b).

The concentrations of both the 20 and $75 \mathrm{~nm}$ particles decreased with distance from the road, with the rates for the open transect (Fig. 7b) higher than for the residential area (Fig. 7c). Qualitatively comparing the QUIC simulations and the measurements in both transects, the decay rates appeared to be similar, though initial concentrations and differences in the mixing zones led to some offset in the rates.

\section{Summary}

At the local-scale, features such as noise barriers, trees, and buildings can have dramatic effects on the initial dispersion of pollutants from roadways, influencing concentrations up to several hundred meters from the road. For winds perpendicular to the roadway, under neutral stability atmospheric conditions, noise barriers appeared to influence dispersion patterns in three ways. First, the plume moved up and over the noise barrier, simulating an elevated source. As with elevated sources, plume reattachment occurred further downwind. Second, a recirculation wake region formed in the lee of the barrier, and concentrations were reduced compared with an open area with no barrier. Third, when the elevated plume encountered other downwind obstacles (e.g., trees or buildings), increased mixing occurred leading to decreased pollutant concentrations. Further research is needed to identify the effects of these structures under varying wind and topographic conditions.

Predictions from the diagnostic wind field and dispersion model, QUIC, were compared with mobile measurements of UFPs in this study. The comparisons suggested that QUIC adequately reproduced the complex flow and dispersion patterns around the roadside structures, demonstrating potential value as a diagnostic tool for this application. Further evaluation of this model will likely be necessary before using this model in regulatory and urban planning applications.

\section{Acknowledgments}

This work reflects the collaboration of many individuals working with EPAs near-road program. In particular, the authors appreciate the direction and support of Dr. Dan Costa, US EPA's national program director for air, for leading the near-road 
research program. The authors also thank Eben Thoma and Jason Weinstein of EPA's Office of Research and Development and Tom Long and Richard Snow of ARCADIS Inc. for their assistance in organizing, implementing and interpreting the field study measurements taken in the broader near road study in Raleigh, NC, and the North Carolina Lions Club for the Blind for access to portions of the field site used in this study.

\section{Disclaimer}

The research presented here was performed under the Memorandum of Understanding between the US Environmental Protection Agency (EPA) and the US Department of Commerce's National Oceanic and Atmospheric Administration (NOAA) under Agreement number DW13921548. This work constitutes a contribution to the NOAA Air Quality Program. Although it has been reviewed by EPA and NOAA and approved for publication, it does not necessarily reflect their policies or views. The US Government's right to retain a nonexclusive royalty-free license in, and to any copyright is acknowledged.

\section{References}

Bagal, N.L., Pardyjak, E.R., Brown, M.J., 2004. Improved upwind parameterization for a fast response urban wind model. In: 84th American Meterological Society Conference: Symposium on Planning, Nowcasting, and Forecasting in the Urban Zone. Seattle, WA. January, 7.4, 5pp.

Benson, P.E., 1992. A review of the development and application of the CALINE3 and 4 Models. Atmospheric Environment 26, 379-390.

Bowker, G.E., Gillette, D.A., Bergametti, G., Marticorena, B., 2006. Modeling flow patterns in a small vegetated area in the northern Chihuahuan Desert using QUIC (Quick Urban \& Industrial Complex). Environmental Fluid Mechanics 6, 359-384.

Bowker, G.E., Gillette, D.A., Bergametti, G., Marticorena, B., Heist, D.K., 2007. Sand flux simulations at a small scale over a heterogeneous mesquite area of the northern Chihuahuan Desert. Journal of Applied Meteorology and Climatology, in press.

Cadle, S.H., Mulawa, P., Hunsanger, E.C., Nelson, K., Ragazzi, R.A., Barrett, R., Gallagher, G.L., Lawson, D.R., Knapp, K.T., Snow, R., 1999. Light-duty motor vehicle exhaust particulate matter measurement in the Denver, Colorado area. Journal of the Air and Waste Management Association 49 PM-164-174.

Durbin, T.D., Smith, M.R., Norbeck, J.M., Truex, T.J., 1999. Population density, particulate emission characterization, and impact on the particulate inventory of smoking vehicles in the South Coast Air Quality Management District. Journal of the Air and Waste Management Association 49, 28-38.
Gowardhan, A.A., Brown, M.J., Williams, M.D., Pardyjak, E., 2006. Evaluation of the QUIC Urban Dispersion Model using the Salt Lake City URBAN 2000 Tracer Experiment Data-IOP 10. In: Sixth Symposium on the Urban Environment/14th Joint Conference on the Applications of Air Pollution Meteorology with the Air and Waste Management Association. Atlanta. January, J6.3, 13pp.

Grimmond, C.S.B., King, T.S., Roth, M., Oke, T.R., 1998. Aerodynamic roughness of urban areas derived from wind observations. Boundary-Layer Meteorology 89, 1-24.

Hölscher, N., Höffer, R., Niemann, H-J., Brilon, W., Romberg, E., 1993. Wind tunnel experiments on micro-scale dispersion of exhausts from motorways. Science of the Total Environment 134, 71-79.

Jerrett, M., Burnett, R., Pope, C.A., Krewski, D., Bruce, K., Thurston, G., Shi, Y., Finklestein, N., Calle, E.E., Thun, M.J., 2005. Spatial analysis of air pollution and mortality in Los Angeles. Epidemiology 16 (6).

Kalthoff, N., Baumer, D., Corsmeier, U., Kohler, M., Vogel, B. 2005. Vehicle-induced turbulence near a motorway. Atmospheric Environment 39, 5737-5749.

Khlystov, A., Ma, Y., 2006. An on-line instrument for mobile measurements of the spatial variability of hexavalent and trivalent chromium in urban air. Atmospheric Environment 40, 8088-8093.

Kittelson, D.B., Watts, W.F., Johnson, J.P., 2004. Nanoparticle emissions on Minnesota highways. Atmospheric Environment 38 (1), 9-19.

Kleeman, M.J., Schauer, J.J., Cass, G.R., 2000. Size and composition distribution of fine particulate matter emitted from motor vehicles. Environmental Science and Technology $34,1132-1142$.

Lidman, J.K., 1985. Effect of a noise wall on snow accumulation and air quality. Transportation Research Record 1033, 79-88.

Madders, M., Lawrence, M., 1985. The contribution made by vegetation buffer zones to improved air quality in urban areas. In: Hall, D.O., Myers, N., Margaris, N.S. (Eds.), Economics of Ecosystems Management. Dr. W. Junk Publishers, Dordrecht, Netherlands.

McConnell, R., Berhane, K., Yao, L., Jerrett, M., Lurmann, F., Gilliland, F., Kuenzli, N., Gauderman, J., Avol, E., Thomas, D., Peters, J., 2006. Traffic, susceptibility, and childhood asthma. Environmental Health Perspectives 114 (5), 766-772.

Nagendra, S.M.S., Khare, M., 2002. Line source emission modeling. Atmospheric Environment 36, 2083-2098.

Nokes, W.A., Benson, P.E., 1984. Carbon monoxide concentrations adjacent to sound barriers. Office of Transportation Laboratory, California Department of Transportation. Report FHWA/CA/TL-84/04.

Pardyjak, E., Brown, M., 2003. QUIC-URB v1.1 Theory and User's Guide. Los Alamos National Laboratory, Los Alamos, NM.

Pardyjak, E.R., Brown, M.J., Bagal, N.L., 2004. Improved velocity deficit parameterizations for a fast response urban wind model. In: 84th American Meteorological Society Conference: Modeling Urban Land Surfaces and Buildings: Part 2, Seattle, WA. January, 7.4, 5pp.

Paul-Carpenter, S., Barboza, M.J., 1988. Effects of highway noise barriers on carbon monoxide levels. In: 81st Annual meeting of the Air Pollution Control Association (APCA), Dallas, TX, June 1988. 
Pearson, R.L., Wachtel, H., Ebi, L., 2000. Distance-weighted traffic density in proximity to a home is a risk factor for leukemia and other childhood cancers. Journal of the Air and Waste Management Association 50, 175-180.

Peters, A., von Klot, S., Heier, M., Trentinaglia, I., Hormann, A., Wichmann, E., Lowel, H., 2004. Exposure to traffic and the onset of myocardial infarction. New England Journal of Medicine 351, 1721-1730.

Sapkota, A., Buckley, T.J., 2003. The mobile source effect on curbside 1,3-butadiene, benzene, and particle-bound polycyclic aromatic hydrocarbons assessed at a tollbooth. Journal of the Air and Waste Management Association 53, 740-748.

Singh, B., Pardyjak, E.R., Brown, M.J., Williams, M.D., 2006. Testing of a Far-wake Parameterization for a Fast Response Urban Wind Model. In: Sixth Symposium on the Urban Environment/14th Joint Conference on the Applications of Air Pollution Meteorology with the Air and Waste Management Association, Atlanta, January, J8.4A, 11 pp.

Tan, K.T., Lepp, N.W., 1977. Roadside vegetation: an efficient barrier to the lateral spread of atmospheric lead? Arboricultural Journal 3 (2), 79-85.
Veerabhadra Swamy, K.T., Lokesh, K.S., 1993. Lead dispersion studies along highways. Indian Journal of Environmental Health 35 (33), 205-209.

Wang, S.C., Flagan, R.C., 1990. Scanning electrical mobility spectrometer. Aerosol Science and Technology 35, 718-727.

Wilhelm, M., Ritz, B., 2003. Residential proximity to traffic and adverse birth outcomes in Los Angeles County, California, 1994-1996. Environmental Health Perspectives 111, 207-216.

Williams, M.D., Brown, M.J., Singh, B., Boswell, D., 2005a. QUIC-PLUME Theory Guide. LA-UR-04-0561.

Williams, M.D., Brown, M.J., Boswell, D., 2005b. QUICPLUME Advanced User's Guide. LA-UR-04-0562.

Zhu, Y., Hinds, W.C., Kim, S.K., Shen, S., Sioutas, C., 2002a. Study of ultrafine particles near a major highway with heavy-duty diesel traffic. Atmospheric Environment 36, 4323-4335.

Zhu, Y., Hinds, W.C., Kim, S.K., Sioutas, C., 2002b. Concentration and size distribution of ultrafine particles near a major highway. Journal of the Air and Waste Management Association 52, 1032-1042. 